\title{
Article \\ Response of Oil Production and Quality to Hedgerow Design in Super-High-Density Olive cv. Arbequina Orchards
}

\author{
Eduardo R. Trentacoste ${ }^{1, *}\left(\mathbb{D}\right.$, David J. Connor ${ }^{2}$ and María Gómez-del-Campo ${ }^{3}$ \\ 1 Estación Experimental Agropecuaria Junín (Instituto Nacional de Tecnología Agropecuaria), \\ Mendoza 5572, Argentina \\ 2 School of Agriculture and Food, University of Melbourne, Melbourne 3010, Australia; \\ djconnor@unimelb.edu.au \\ 3 CEIGRAM/Dpto, Producción Agraria/ETSIAAB, Universidad Politécnica de Madrid, 28040 Madrid, Spain; \\ maria.gomezdelcampo@upm.es \\ * Correspondence: trentacoste.eduardo@inta.gob.ar
}

Citation: Trentacoste, E.R.; Connor, D.J.; Gómez-del-Campo, M. Response of Oil Production and Quality to Hedgerow Design in Super-High-Density Olive cv. Arbequina Orchards. Agronomy 2021, 11, 1632. https://doi.org/ 10.3390/agronomy11081632

Academic Editors: José

Casanova Gascón, Ignasi Iglesias,

Stefano Musacchi and

Salvatore Camposeo

Received: 20 July 2021

Accepted: 14 August 2021

Published: 17 August 2021

Publisher's Note: MDPI stays neutral with regard to jurisdictional claims in published maps and institutional affiliations.

Copyright: (c) 2021 by the authors. Licensee MDPI, Basel, Switzerland. This article is an open access article distributed under the terms and conditions of the Creative Commons Attribution (CC BY) license (https:/ creativecommons.org/licenses/by/ $4.0 /)$
Abstract: An analysis is presented of the response of olive oil production and quality parameters, viz. fatty acids (palmitic, oleic and linoleic acids), phenolic compounds and oxidative stability to hedgerow spacing and orientation in 1-m wide super-high-density orchards of cv. Arbequina. Data reveal strong linear relationships between concentrations of fatty acids and internal irradiance within hedgerows, positive for palmitic and linoleic but negative for oleic acid. The result is a significant vertical trend in oil composition within hedgerows, but small to negligible differences in oil harvested from them in totality. The explanation is found in the small ranges and strongly correlated responses of individual fatty acids that together comprise $98 \%$ of oil mass. Phenolic compounds respond more widely and to higher levels of irradiance than fatty acids and did show increases in NS hedgerows grown at wide row spacing. Oxidative stability shows a similar trend in phenolic compounds. A simulation study that extended the known responses to 2-m wide hedgerows showed that the linkage between fatty acid profiles was maintained with no resultant differences in the oil composition of the total simulated oil harvest. Based on the current understanding of internal irradiance within olive hedgerows, there seems to be little opportunity to manage oil quality by orchard structure.

Keywords: super-high density (SHD); row spacing; orientation; internal irradiance; fatty acids; phenols

\section{Introduction}

Traditionally, olive plantations were established with wide spacing $(>7 \mathrm{~m})$ and trees were trained to open-vase shapes with low canopy density, because most were grown in low rainfall areas under dryland conditions [1]. In these olive orchards, irradiance is not a factor limiting fruit formation or yield, but it did become so in the first super-high density (SHD) hedgerow orchards that were established in the mid-90s with inter- and intra-row spacings of 3-4 $\mathrm{m}$ and 1.5-2 $\mathrm{m}$, respectively [2]. This type of orchard was designed to be irrigated and harvested with modified grape machines requiring that hedgerows should be maintained below $2.8 \mathrm{~m}$ height and around $1 \mathrm{~m}$ width. These hedgerows require special attention in design and management to maximize the proportion of canopies under high irradiance required for high production and sanitation. It was soon observed, however, that irradiance in the lower parts of canopies was often limiting production, giving rise to the first studies of the effect of irradiance and shading on oil production [3]. Oil quality responses to hedgerow design and canopy environment have been scarcely studied despite greater demand for olive oil, as the premier vegetable oil, for components with nutritional, therapeutic and organoleptic properties [4].

The oil quality parameters considered here comprise the three major fatty acids, palmitic, oleic and linoleic acids; phenolic compounds as a group; and oxidative stability. The first three, comprising around $98 \%$ of oil mass, are produced in-situ from assimilate 
imported from leaves. Numerous studies have shown that the beneficial nutritional and therapeutic properties of olive oil are related to high concentration of oleic acid [5]. In addition, oleic acid shows less susceptibility to oxidation than polyunsaturated acids. Phenolics are complex molecules whose concentrations, according to some authors, increase in olive oil in association with greater irradiance of the fruit [6-8]. Recently, the phenolic composition in olive fruits and oil and their positive contribution to the oxidative stability of oil and its anti-cancerogenic and organoleptic (bitter and pungent) attributes have attracted considerable attention [9].

The impact of orchard design on oil quality is related firstly to cultivar, because they differ largely, and secondly to irradiance surrounding olive fruits during oil formation [10]. Irradiance determines the photosynthesis of surrounding leaves and the consequent flow of assimilates to the fruit during fruit filling. Irradiance is also one determinant, along with convective cooling, of fruit temperature, which determines assimilate supply, enzymatic activity and the chemical synthesis of oil quality components. The parameters of orchard design that mainly modify within-canopy irradiance are row spacing, row orientation, canopy height, canopy width and foliage density (porosity). Intra-row spacing, by contrast, determines the time taken to develop complete hedgerows [11].

The choice of the most suitable cultivar for individual growing conditions is currently determined mainly by the quantity of oil produced, but oil quality is becoming increasingly important. During the last 10 years, studies have evaluated productive and vegetative responses of various cultivars in SHD orchards under a wide range of environments (Spain [12,13]; Italy [14,15]; Tunisia [16]), all with the similar objective to find alternatives to $\mathrm{cv}$. Arbequina. Unfortunately, few cultivars have the required characteristics of low vegetative vigor and early and consistent production that are suited to SHD orchards [2] so $\mathrm{cv}$. Arbequina remains the most widely used. Virgin olive oil (VOO) from cv. Arbequina has high acceptance in international markets due to its excellent sensory quality and its characteristic softness, despite low phenolic and oleic acid concentrations and resultant lower oxidative stability. So the question remains if hedgerows could be designed to achieve advantage in oil quality as well as quantity.

The objective of this work is to study the relationship between amount and quality of harvested oil and the orchard design of SHD orchards through its impact on radiation environment within component hedgerows. For this, we first present observations, from 1-m wide hedgerows of various row spacing and orientation, of the spatial distribution of oil quality and the resultant accumulated quality of harvested oil. Second, we present analyses of relationships between the distribution of oil quality parameters and simulated irradiance within the hedgerows and measured fruit temperature. Finally, we use a simulation model of within-canopy irradiance to explore oil quality response in contrasting hedgerow dimensions with varied spacings, heights and orientations. This work is an extension of an earlier study [17] that dealt with other aspects of fatty acid composition in oil from the NS-oriented hedgerows also reported here.

\section{Materials and Methods}

\subsection{Experiments}

The experiments were conducted in SHD olive (cv. Arbequina) hedgerow orchards planted in 2008 near La Puebla de Montalbán ( $39^{\circ} 53^{\prime} \mathrm{N}, 4^{\circ} 27^{\prime} \mathrm{W}, 479$ m.a.s.l.), Toledo, central Spain. Two experimental orchards, separated by approximately $100 \mathrm{~m}$, were established with rows oriented NS and EW, respectively. Each orchard, planted at three row spacings: $2.5,3.75$ and $5.0 \mathrm{~m}$, comprised 7 adjacent rows with 48 trees per row spaced at $1.3 \mathrm{~m}$.

The climate of the region is semi-arid with average annual rainfall of $359 \mathrm{~mm}$ concentrated from autumn to spring and an average annual temperature of $16.0^{\circ} \mathrm{C}$. The soil was a clay-loam of three layers; an A horizon $(0-0.15 \mathrm{~m})$, a Bt horizon $(0.15-0.40 \mathrm{~m})$ and a carbonaceous $C$ horizon that impeded root penetration. Orchards were managed similarly using standard commercial practice. Supplementary irrigation to ensure that trees did not suffer 
water deficit was applied from March to October using single drip lines $3.0 \mathrm{~L} \mathrm{~h}^{-1}$ at $0.5 \mathrm{~m}$ spacing. This required consideration of both reference evapotranspiration and rainfall.

From planting until winter 2012, central leaders were trained on bamboo stakes $2.5 \mathrm{~m}$ tall. From the end of season 2012, branches that extended into the alleys or above $2.5 \mathrm{~m}$ height were removed annually to facilitate the passage of the harvester. All hedgerows were restricted to similar dimensions by topping and lateral pruning and consequently had similar structures (ca. $2.5 \mathrm{~m}$ height $\times 1.0 \mathrm{~m}$ width) and also average horizontal porosity (ca. 20\%) 5 years after planting. Other experimental details can be consulted in Trentacoste et al. [18].

\subsection{Harvest and Parameters Evaluated}

On 5 November 2012 and 29 October 2013, harvests were made in three randomly selected trees of the central row of 2.5, 3.75 and $5 \mathrm{~m}$ spacing in both NS and EW orientations. All fruits were harvested separately in five height layers $(0.0-0.4,0.4-0.8,0.8-1.2$, 1.2-1.6 and 1.6-2.0 $\mathrm{m}$ above the base of the canopy at $0.5 \mathrm{~m}$ above ground) from either side of the trees and weighed immediately. Above $2.0 \mathrm{~m}$ (top), where canopies were discontinuous, fruits were harvested from both sides together. A sample of $2 \mathrm{~kg}$ was collected from each sample. When the fruit harvest from the selected trees was less than $2 \mathrm{~kg}$, the sample was completed with fruits from the same height and side of adjacent trees.

Later, in the laboratory, 3 sub-samples of ca. $25 \mathrm{~g}$ were separated from each sample, and fruits were counted. Maturity index (MI, value 0 to 7 ) was determined by classifying the fruits according to skin and pulp color following Uceda and Frías [19]. Each sample was weighed fresh and then dried in a forced-air oven at $105^{\circ} \mathrm{C}$ for $42 \mathrm{~h}$ for the determination of oil content on a dry weight basis by nuclear magnetic resonance (MiniSpec MQ-10; Bruker, Madison, WI, USA) using the method described by del Río and Romero [20]. Oil production was estimated as the product of harvest weight and fruit oil content.

Oil was extracted from each $1 \mathrm{~kg}$ of sampled olives using an Abencor analyzer (Comercial Abengoa S.A., Seville, Spain), decanted into graduated tubes, filtered through filter paper and stored at $-4{ }^{\circ} \mathrm{C}$ until analysis. Fatty acid and phenolic concentrations were evaluated according to European Union standard methods. An automated Methrom Rancimat 679 apparatus (Methrom Co., Basel, Switzerland) was used to determine the oxidative stability with a $2.5 \mathrm{~g}$ oil sample. Overall hedgerow oil quality parameters were calculated as mean concentration weighted according to oil yield across sides and layers.

The temperature of exposed fruits on canopy walls was measured at 8 and 15 solar time (h) on two days during the fruit maturity period in 2012 (20 September and 2 October) and in 2013 (11 September and 16 October). Measurements were made in three fruits located in three canopy positions (i.e., lower $<0.5 \mathrm{~m}$ height, central 1-2 $\mathrm{m}$ height and upper $<2 \mathrm{~m}$ height) from both sides of each hedgerow spacing and orientation. A fine thermistor (6 mm long $\times 1 \mathrm{~mm}$ diameter) connected to a data logger (Phywe, Germany) was inserted into the pulp on the shaded side of each fruit. Average fruit temperature for corresponding heights of the measured fruits was related to irradiance simulated on each occasion (day and hour) by the hedgerow structure and interception model described in the following section.

\subsection{Simulations}

A model [21] was used to estimate average irradiance on foliage at many points $(19 \mathrm{~h} \times 19 \mathrm{w}=361)$ in the vertical plane of row width. They were averaged over defined periods for corresponding vertical sections ( $0.4 \mathrm{~m}$ deep) on both sides of the $1-\mathrm{m}$ wide hedgerows corresponding to volumes $\left(0.2 \mathrm{~m}^{3}\right)$ from which fruit were removed for analysis of oil production and quality. From these data, relationships were established between yield and quality parameters against mean daily horizontal irradiance $\left(\mathrm{mol} \mathrm{PAR} \mathrm{m}{ }^{-2}\right.$ ) under clear-sky conditions for each hedgerow structure from flowering (DOY 150) to both pit hardening (DOY 190) and fruit harvest (DOY 310). Phenological development was recorded during 2012 and 2013. 
The same model, including the oil production and quality relationships established from the experimental data, was then used to investigate the effect of a wider range of taller and wider hedgerow systems on oil quality.

\subsection{Statistical Analysis}

Data from each orchard were independently subjected to analysis of variance using Infostat version 1.5 (Universidad Nacional de Córdoba, Argentina). The means were separated using the LSD-test for a level of significance $\alpha=0.05$. Linear or linear-plateau functions were fitted using the non-linear routing of GraphPad Prism version 5.01 software (La Jolla, CA, USA) to describe the relationships between fruit maturity, oil production and quality parameters with hedgerow height and simulated irradiance.

\section{Results}

\subsection{Response of Main Fatty Acids of Fruit to Canopy Position in Hedgerows of Varying Row Spacing and Orientation}

The vertical profiles of concentrations of the main fatty acids on both sides of hedgerows cv. Arbequina planted at three row spacings (5.0, 3.75 and $2.5 \mathrm{~m}$ ) are presented in Figure 1. These observations reveal that a single linear model captured the vertical trend on both $\mathrm{E}$ and W sides of NS hedgerows. The concentrations of palmitic and linoleic acids decreased linearly from the top to the base of the hedgerows while that of oleic acid increased. Hedgerows spaced at 5.0 and $3.75 \mathrm{~m}$ showed less response to the height of the canopy (i.e., lower slope values) relative to the $2.5-\mathrm{m}$ spacing. In EW hedgerows, the profiles of palmitic and oleic acids but not of linoleic acid showed less variation from top to base on both $\mathrm{S}$ and $\mathrm{N}$ sides of hedgerows and were not significantly related to hedgerow height. In EW hedgerows, oil composition was different between $\mathrm{S}$ and $\mathrm{N}$ sides in response to row spacing. In hedgerows spaced at 5.0 and $3.75 \mathrm{~m}$, palmitic and linoleic acids were higher and oleic acid lower on $\mathrm{S}$ than on $\mathrm{N}$ sides. At 2.5-m row spacing both sides showed similar responses to canopy height.

\section{NS Hedgerows}
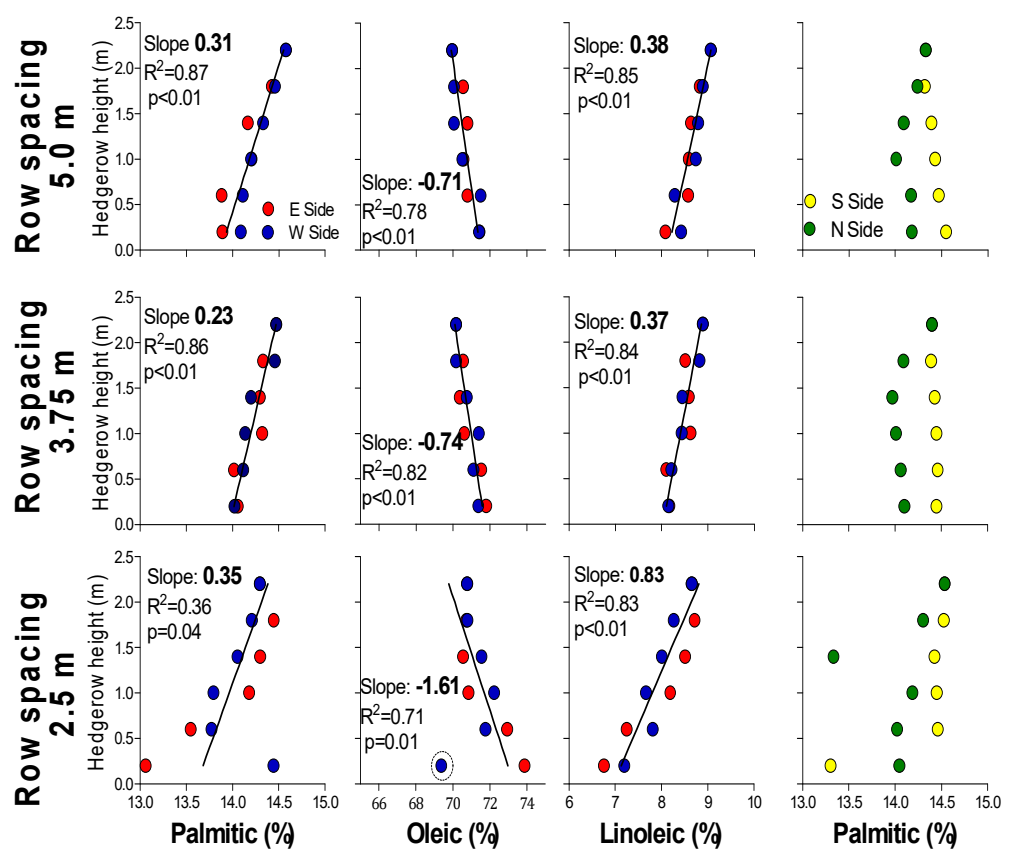

EW Hedgerows

Palmitic (\%)

Oleic (\%)

Palmitic (\%)
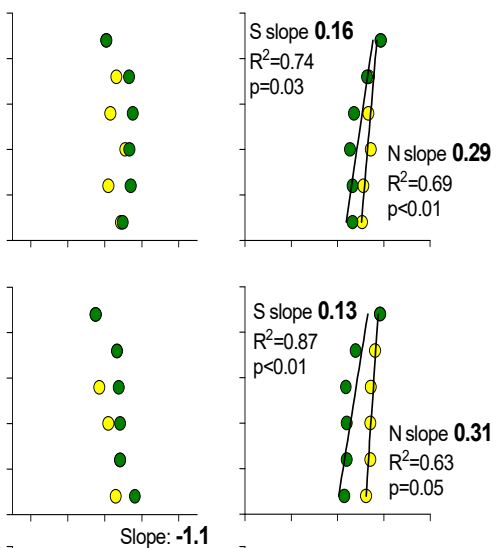

Figure 1. Major fatty acid contents of oils extracted from fruits harvested in vertical layers on E (red symbols) and W (blue symbols) sides of NS hedgerows and on S (yellow symbols) and N (green symbols) sides of EW hedgerows, both planted at three row spacings (5.0, 3.75 and $2.5 \mathrm{~m}$ ). Each point is the average of two seasons (2012 and 2013). A single regression fitted 
to both sides of the hedgerow is shown when the individual coefficients of regression were not significantly different at $p \leq 0.05$. Data inside the circles were not considered in the relationship. Regression lines to data from single or both sides of hedgerows are shown when significant. Data from NS hedgerows are adapted from Figure 3 in Trentacoste et al. [17].

\subsection{Response of Hedgerow Oil Yield and Quality to Spacing and Orientation}

Oil yield decreased with increasing row spacing (Figure 2). Production of 5-m spaced hedgerows decreased on average in 2012 and 2013 by $34 \%$ and $26 \%$ relative to the $2.5-\mathrm{m}$ spacing in NS and EW hedgerows, respectively. There were no significant differences in oil produced within each orientation and year for hedgerows spaced at 5 or $3.75 \mathrm{~m}$.

NS Hedgerows
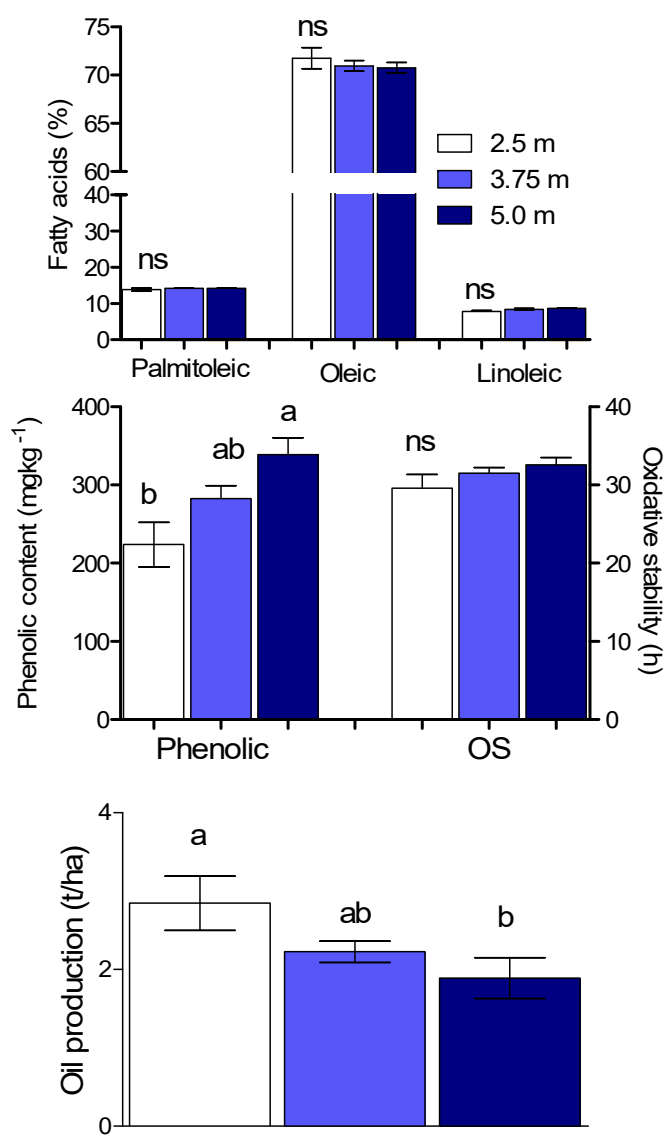

\section{EW Hedgerows}
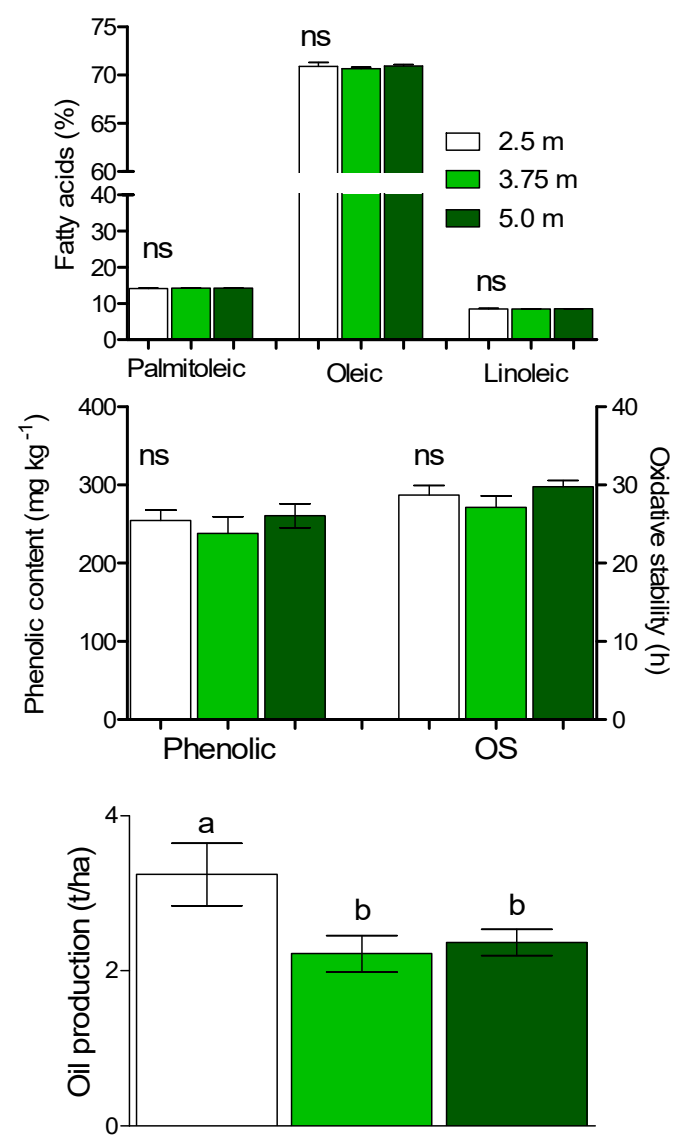

Figure 2. Weighted mean concentrations of main fatty acids and phenolic concentrations together with the oxidative stability (OS) of oils extracted from 2.4-m tall $\times 1$.2-m wide NS (left) and EW (right) hedgerows of cv. Arbequina planted at three row spacings (5.0, 3.75 and $2.5 \mathrm{~m}$ ). Each bar is the average of the 2012 and 2013 seasons in Toledo, Spain. The average oil production per ha during 2012 and 2013 is also shown. NS and EW results were independently subjected to ANOVA. Columns labelled ns are not statistically different; those with different letters are at $p<0.05$.

Despite differences in vertical profiles of quality parameters in response to row spacing and orientation (Figure 1), the accumulated differences between oil quality harvested from individual orchards of different structure were small. The data in Figure 2 show that oil production per ha of these mature hedgerows of height and width $(2.5$ and $1.2 \mathrm{~m}$, respectively) was higher in row spacing of $2.5 \mathrm{~m}$ than $5.0 \mathrm{~m}$, while maintaining similar fatty acid concentrations and oxidative stability for the six combinations of three row spacings $(2.5,3.75,5.0 \mathrm{~m})$ and two orientations (NS and EW). Significant responses to orchard structure were only established for phenolic content in NS hedgerows, which reached $350 \mathrm{mg} \mathrm{kg}^{-1}$ in the widest $(5 \mathrm{~m})$ spacing relative to a mean of $224 \mathrm{mg} \mathrm{kg}^{-1}$ in the narrowest spacing $(2.5 \mathrm{~m})$. 


\subsection{Responses of Oil Production and Quality to Irradiance within Hedgerows}

The relationships between oil yield, fruit maturity and oil composition and simulated irradiance from flowering to harvest for both orientations were captured significantly by linear models (Figure 3). Irradiance was simulated in other short periods (i.e., from flowering to pit hardening and from pit hardening to harvest) and their relationships to oil yield and oil compositions explored. They did not, however, offer better associations with respect to the complete period.
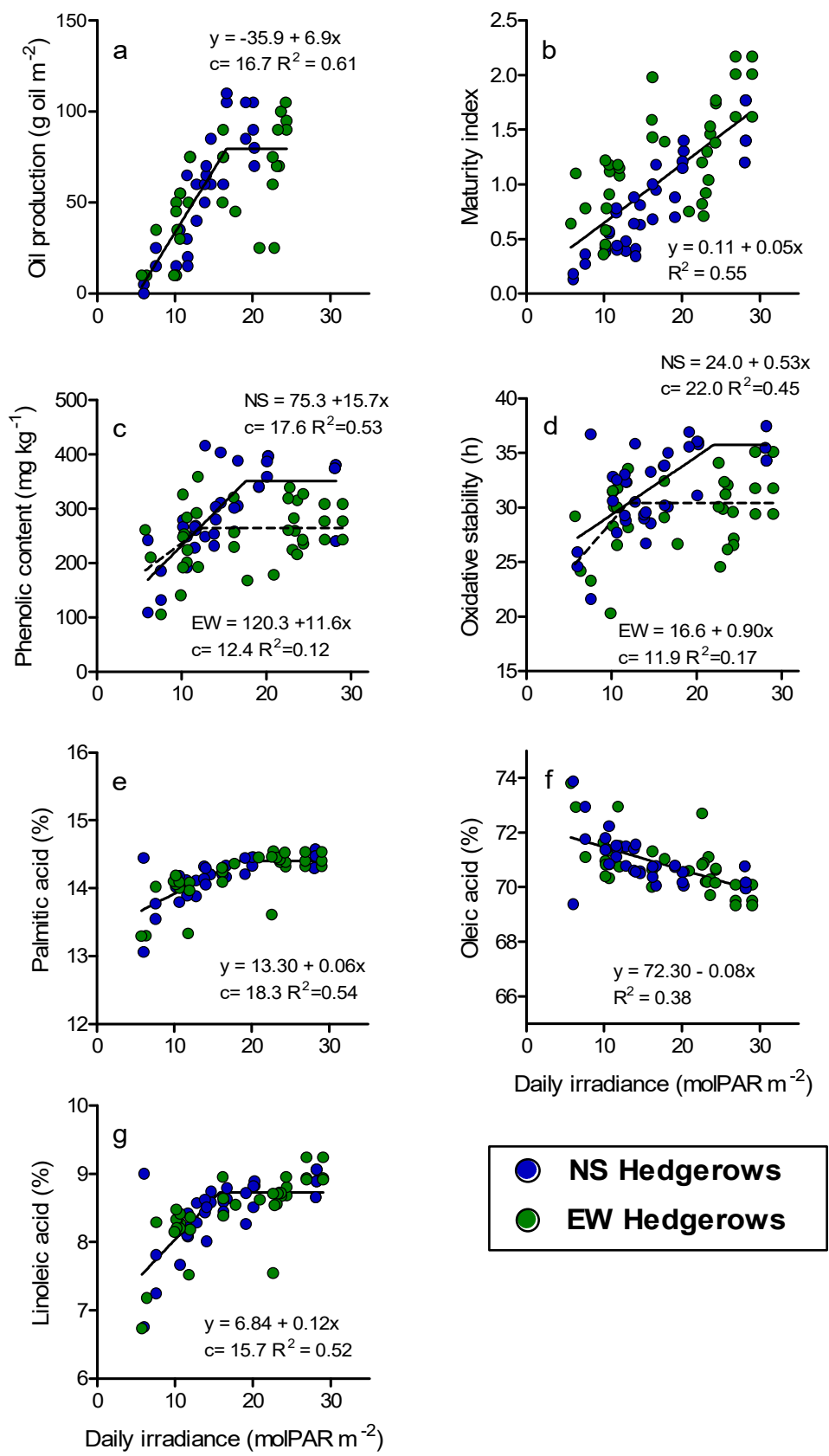

Figure 3. Response of oil production (panel a), maturity (b), phenolic concentrations (c), oxidative stability (d) and main fatty acid composition ( $\mathbf{e}-\mathbf{g})$ of olive oil obtained from mature fruits located at various heights on both sides of NS and EW hedgerows planted at three row spacings (5.0, 3.75 and $2.5 \mathrm{~m}$ ) in relation to simulated foliage irradiance. Each point is the average for the 2012 and 2013 seasons. Parameter $\mathrm{c}$ is the daily irradiance at which the relationship changes slope. Data from NS hedgerows included in plots (e-g) are adapted from Trentacoste et al. [17]. 
A bilinear model fitted the relationship between oil production and irradiance for data from all hedgerow spacings and orientations. The linear response $\left(\mathrm{R}^{2}=0.61 ; p<0.01\right)$

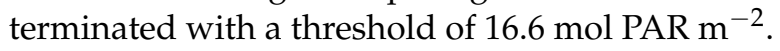

Fruit maturity increased strongly and linearly for both orientations over the entire irradiance range $\left(\mathrm{R}^{2}=0.55 ; p<0.001\right)$. Similarly, strongly linear or bilinear responses of palmitic, oleic and linoleic acid with daily irradiance were common for both orientations. In the case of palmitic and linoleic acids, concentration increased linearly with irradiance to a maximum at PAR of 18.3 and $15.7 \mathrm{~mol} \mathrm{~m}^{-2}$, respectively, but for oleic acid, it decreased over the entire irradiance range.

Bilinear relationships were also obtained for both phenolic concentration and oxidative stability but with distinction between hedgerow orientations. In this case, thresholds for NS hedgerows were 17.6 and $22.0 \mathrm{~mol} \mathrm{PAR} \mathrm{m}^{-2}$, markedly higher than 12.4 and $11.9 \mathrm{~mol}$ PAR $\mathrm{m}^{-2}$ for EW hedgerows.

\subsection{Relationship between Irradiance and Fruit Temperature}

Observations of fruit temperature made morning and afternoon on two days at three canopy heights in hedgerows of three row spacings and both NS and EW orientations are presented, along with corresponding (day and hour) simulated irradiance in Figure 4. Analysis reveals positive relationships between fruit temperature and irradiance in the morning that were not repeated in the afternoon when fruit temperature was more variable. In the morning, the test of slope and intercept for both NS and EW relationships showed no significant difference between orientation ( $p$-value 0.1125 and 0.4571 for slopes and intercepts, respectively). In contrast during afternoon, fruit temperature was highly variable and not related to irradiance, regardless hedgerow orientation. Fruit with temperature below $20^{\circ} \mathrm{C}$ were not included in the analysis.
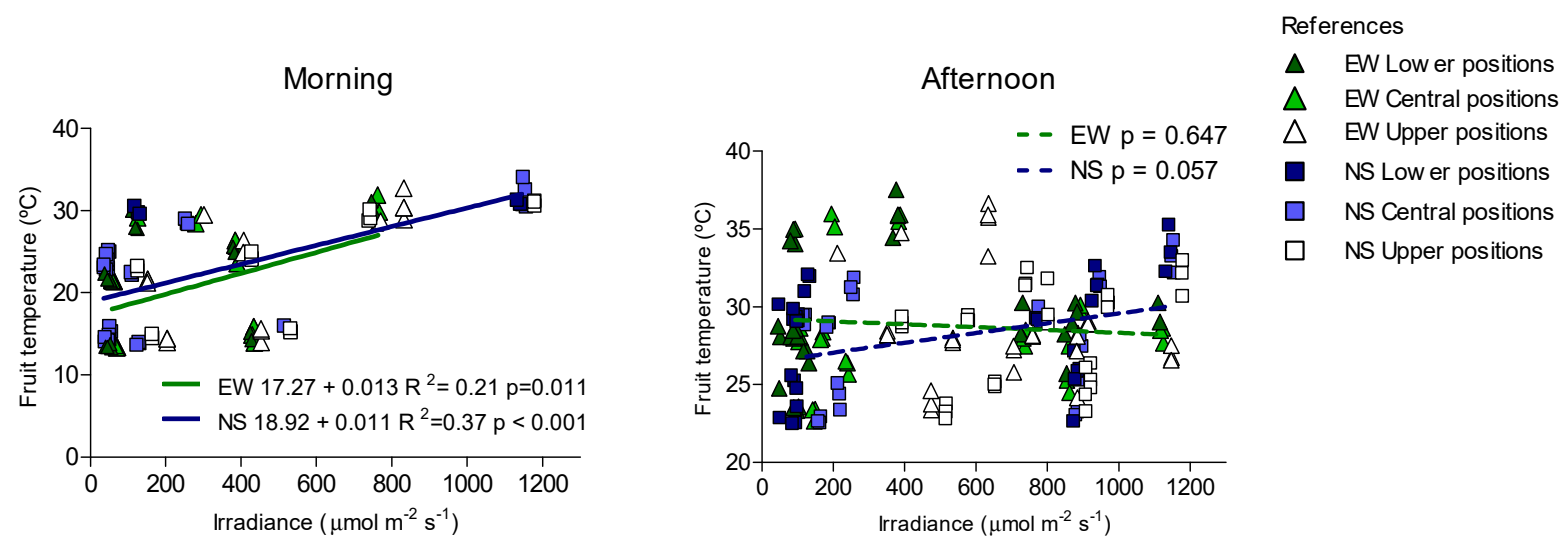

Figure 4. Relationship between fruit temperature measured on fruit located at three heights and corresponding simulated irradiance on both sides of NS and EW hedgerows planted at three row spacings (5.0, 3.75 and $2.5 \mathrm{~m}$ ). Fruit temperature was measured on two occasions (morning and afternoon, 8 and $15 \mathrm{~h}$ solar time) on each of two days during oil synthesis during 2012 and 2013. Solid and dashed lines are significant and no significant regressions, respectively.

\subsection{Simulations of Olive Orchard Design for Oil Quality}

The simulation model, parameterized with the oil-quality responses presented in Figure 3, was used to evaluate the impact of a broader range of structure on oil quality of entire SHD orchards. Here we present simulations of the response of oil quality in taller ( 3 and $4 \mathrm{~m}$ ) and wider $(2 \mathrm{~m}$ ) hedgerows that are still suited to mechanical overhead harvesting. The relationships between fruit quality parameters and irradiance were established for consecutive vertical volumes of $0.2 \mathrm{~m}^{3}$ on both sides of 1 -m wide hedgerows $(\mathrm{h}=0.4$, $\mathrm{w}=0.5 .1=1 \mathrm{~m})$. Analysis of wider hedgerows assumes that the same relationships also apply to inner volumes of similar dimensions within 2-m wide hedgerows. Attention to the fitted relationships presented in Figure 3 is appropriate to these simulations. By 
neglecting the outliers, the fitted lines define narrow ranges of response for fatty acids, especially the dominant oleic acid, but wider ones for maturity, phenolic compounds and oxidative stability. From the base value at irradiance of $5 \mathrm{~mol} \mathrm{PAR} \mathrm{m}^{-2}$, the percentage responses for palmitic, oleic and linoleic acids are $5.9,-2.8$ and $17.3 \%$ and for maturity index 0.35 , calculated from a single regression obtained for both hedgerow orientations. Greater responses for phenolic compounds (129 and 48\%) and oxidative stability (34 and $29 \%$ ) varied between NS and EW orientations, respectively.

The analysis, presented in Figure 5, reveals similar fatty acid profiles in the four combinations of height and orientation but differences in phenolic concentration (large) and oxidative stability (smaller) that increase with row spacing in NS but not in EW hedgerows. These responses are in correspondence with the experimental observations presented in Figure 2.

3-m Height and 2-m Width NS Hedgerows EW Hedgerows

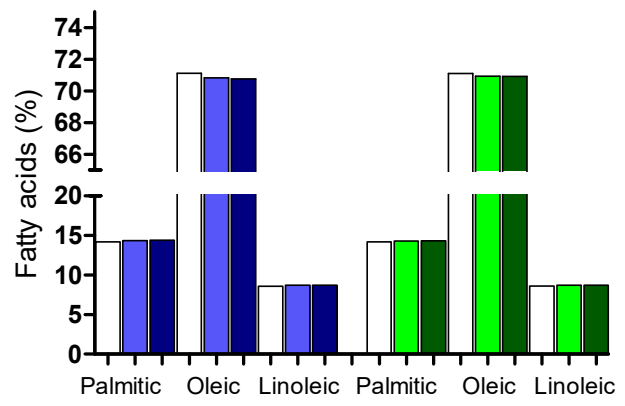

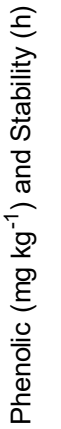

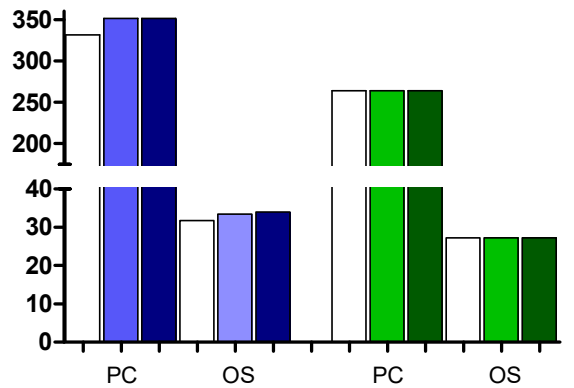

4-m Height and 2-m Width NS Hedgerows EW Hedgerows

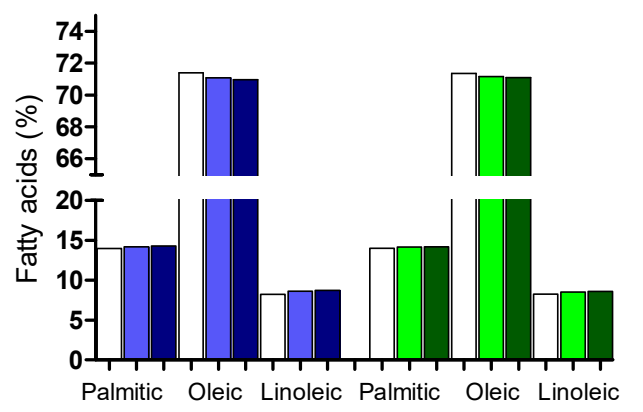

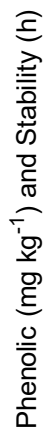

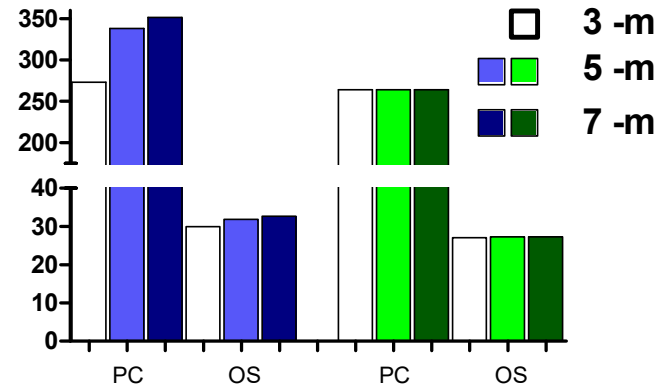

Figure 5. Simulated oil quality; concentrations of palmitic, oleic and linoleic acids; phenolic compounds (PC); and oxidative stability (OS) of 2-m wide hedgerows of 3- and 4-m height, respectively, each at three row spacings (3, 5 and $7 \mathrm{~m})$ and two row orientations (NS and EW) in response to internal hedgerow irradiance during the fruit-filling period (DOY 150-310) at $39.9^{\circ} \mathrm{N}$ (see Figure 3).

\section{Discussion}

Virgin olive oil (VOO) contains more components that those that confer specific organoleptic and healthy properties. Fatty acids (glycerols) are the major components, comprising more than $98 \%$ of oil mass. VOO is considered healthy for human consumption because most of its fatty acids, of which oleic acid is the most important, are unsaturated [22]. The minor components that represent less than $2 \%$ of content include more than 230 chemical components, which have strong impacts on health and taste [4]. The important antioxidant properties of $\mathrm{VOO}$ are provided by carotenes and phenolic compounds. The latter, although in minor concentration, have attracted considerable attention for their strong relationship to anti-cancerogenic and organoleptic (mainly bitter and pungent sensory notes) characteristics of VOO [9]. In this study, oleic acid comprised $69-74 \%$ of oil content (Figure 1), consistent with the commercial quality specifications of VOO, while total phenolic content varied between $105-416 \mathrm{mg} \mathrm{kg}^{-1}$ (Figure 3). These values are similar to those reported for this cultivar in the similar thermal (cold) environment of Lerida [23]. 


\subsection{Response of Hedgerow Oil Yield and Quality to Spacing and Orientation}

Reducing the distance between rows increases tree density, row length and canopy external area per unit orchard area. It also reduces irradiance, especially low in canopies, but increases oil production per ha depending upon row height and width (Figure 2). Those data reveal clearly that these mature hedgerows of height and width (2.5 and $1.2 \mathrm{~m}$, respectively) had large differences in oil production but with similar fatty acid concentration for the six combinations of three row spacings $(2.5,3.75,5.0 \mathrm{~m})$ and two orientations (NS and EW), despite the existence of significant spatial variation within the hedgerows (Figure 1).

Responses at the orchard level to increasing row spacing were, however, recorded for phenolic compounds in NS but not EW hedgerows (Figure 2). This increase in sensory aspects of oil quality would, however, be achieved at significant yield loss, $150 \%$ relative to the $2.5 \mathrm{~m}$ spacing. Rodrigues et al. [24] report a detailed study of oil quality parameters from the first four harvests (i.e., from 4th to 7 th years after planting) of cv. Arbequina hedgerows planted at three row spacings $(4.0,3.5$ and $3.0 \mathrm{~m})$ and intra-row spacing of $1.5 \mathrm{~m}$ at Valladolid, Spain. Samples of fruit were collected by hand, presumably equally from all exposed surfaces. No information is provided on the orientation, height or width of the rows. Considering their last harvest when the hedgerows would be most formed, there were no differences in oleic acid (mean 79\%) between row spacing, whereas phenolic concentration showed a small positive response, increasing from a mean of $92 \mathrm{mg} \mathrm{kg}^{-1}$ for $3.0-\mathrm{m}$ and $3.5-\mathrm{m}$ spacing to $103 \mathrm{mg} \mathrm{kg}^{-1}$ at $4.0 \mathrm{~m}$.

\subsection{Within-Canopy Responses of Oil Production and Quality to Irradiance}

The vertical profiles of oil production and level of main fatty acids on both sides of NS and EW hedgerows (Figure 1) were successfully explained by common responses to simulated mean daily irradiance (Figure 3), even though it is distributed asymmetrically in EW hedgerows. The results indicate that fruits more exposed to sunlight mature more quickly with greater oil content and different fatty acid and phenolic composition, with resultant greater oxidative stability.

Palmitic and linoleic acid concentrations increased linearly with daily irradiance while the concentration of oleic acid, although with smaller response, was negatively associated with irradiance. The response of palmitic, oleic and linoleic acids covered a very narrow range of $5 \%, 3 \%$ and $17 \%$ over the responsive range to 18 and 12 mol PAR $\mathrm{m}^{-2}$ in NS and EW hedgerow, respectively. Similarly, Rousseaux et al. [10] observed a positive increase of palmitic and linoleic acid concentrations with daily irradiance in oils extracted from fruits collected from six contrasting canopy heights in olive cv. Arbequina, whereas oleic acid concentration was negatively related within a narrow range (10\%). The modulation of carbon supply on fatty acid composition has been recognized in a wide range of species $[25,26]$. It seems that higher irradiance increases $(1)$ concentrations of palmitic and stearic acids in fruit, which are the precursors of oleic acid and (2) the further desaturation of oleic to form linoleic acid. Taken together, this would explain the greater oleic acid concentration in less-illuminated lower canopies and the reverse trend for palmitic and linoleic acids (Figure 1). In olive, a linear association between fatty acid content and irradiance has been reported previously [6,27].

Phenolic compounds are complex molecules whose concentrations increase in olive oil in association with greater irradiance of the fruit $[6,8,27,28]$. Their response was much greater than the other parameters measured here, covering a range of $3 \times$ over the responsive range to 18 and $12 \mathrm{~mol} \mathrm{PAR} \mathrm{m}^{-2}$ in NS and EW hedgerow, respectively. This range of responses explains the increasing response of phenolic compounds to high proportions of high irradiance in orchards planted at wide row spacing as observed in our experimental data (Figure 2). Oxidative stability was less responsive $(1.5 \times)$ to irradiance (Figure 3 ) than phenolic compounds but with similar patterns between orientations. These observations confirm the previously reported positive association between oxidative stability and total phenolic concentration [29]. The positive relationship between irradiance and 
phenolic concentration may be related to several processes (1) an increase in assimilates in well-irradiated fruits raises the metabolic rate and activity of enzymes involved in the biosynthesis of phenolic compounds, such as phenylalanine ammonium lyase [30]; (2) well-irradiated fruits contain more oil with consequent lower water content [21]. Since phenolic compounds are soluble in water, extraction from wetter pastes usually produces oils with lower phenolic concentration. Also, total phenolic concentration decreases during fruit maturation independently of cultivar [31].

In order to study the different response of phenolic and oxidative stability to irradiance in NS and EW hedgerows (Figure 3), we simulated irradiance during the entire fruit-growth period and various component periods. We found that irradiance during component periods did not improve relationship to oil quality parameters over that estimated of the entire fruit growth period. This is surprising given that EW hedgerows, unlike their NS counterparts, do show different irradiance patterns between canopy sides and heights during growing seasons. We attribute the different responses of phenolic compounds and oxidative stability to irradiance in NS to EW hedgerows to limitations in simulation of the average irradiance in relatively large volumes of canopy $\left(0.2 \mathrm{~m}^{3}\right)$ used for the collection of fruit. The most likely explanation, which requires more detailed measurements and modelling for resolution, lies in different distributions of irradiance and fruit within the measured volumes of the contrasting orientations rather than some intrinsic response of $\mathrm{cv}$. Arbequina to row orientation.

\subsection{Irradiance and Fruit Temperature}

Irradiance and fruit temperature varied together in the morning but not in the afternoon, demonstrating that a large number of factors, such as air movement, fruit exposure on canopy, skin colour and fruit size, is involved in determining fruit temperature, in addition to incident irradiance [32]. Similarly, Villalobos et al. [33] showed that fruits and leaves from olive canopies are tightly coupled to the atmosphere, and consequently, the temperature of both organs closely relate to the air temperature.

These factors complicate the construction of a model to explore the response of fruit growth and oil composition to fruit temperature. There is little information on the separate effects of temperature and irradiance on fruit maturity or fatty acid content, despite the known general response of metabolic rate that doubles with each $10{ }^{\circ} \mathrm{C}$ increase in temperature. García-Inza et al. [34] carried out a manipulative experiment over the fruit-growth period in which branches with fruits were individually exposed during short (one month) and long (four months) periods to increments of $5{ }^{\circ} \mathrm{C}$ and $10^{\circ} \mathrm{C}$ above ambient temperature with only slight reduction of solar irradiance. The authors observed that concentrations of palmitic and linoleic acids in oil increased linearly with fruit temperature, while oleic acid concentration decreased. In another study, Sánchez-Lucas [35] evaluated trees growing inside chambers heated $4{ }^{\circ} \mathrm{C}$ above environmental temperature (control), showing that fruit phenolic content decreased with temperature increase in one of two studied years. In the observations reported here, the relationship between fruit temperature and irradiance during the morning was similar in both NS and EW orientations. This suggests that hedgerow design strategies of row spacing and row orientation offer less opportunity to modify fruit temperature than incident irradiance.

In the simulation analyses made in this study, any effect of temperature on oil yield and quality is linked to an unknown extent to irradiance, as a major determinant of fruit temperature.

\subsection{Simulations of Olive Orchards Design for Oil Quality}

The simulation model that was used to establish relationships between oil quality parameters and irradiance within hedgerows (Figure 3) was also used to evaluate the impact of a broader range of structures on the oil quality of entire orchards, optimally managed for water and nutrients. This must, however, be done with caution to avoid extrapolation beyond the assumptions in the model and to restrict analyses to orchard structures that are 
commercially realistic. Here it is important to emphasize that the relationships between fruit quality parameters and irradiance were collected from consecutive vertical volumes of $0.2 \mathrm{~m}^{3}$ ( $0.4 \mathrm{~m}$ depth, $0.5 \mathrm{~m}$ width and $1 \mathrm{~m}$ length) on each side of $1-\mathrm{m}$ wide hedgerows. This orchard design is widely used in Spain and surrounding countries (Portugal, Algeria, Tunisia), although larger hedgerows are more common in other places, e.g., in USA, Argentina and Australia. Analysis of wider hedgerows must assume that the same relationships apply to additional inner volumes of similar dimensions within wider hedgerows. Here we simulate the response of oil quality to taller and wider hedgerows than included in our experiments and yet that are suited to mechanical overhead harvesting.

The analysis, presented in Figure 5, reveals similar fatty acid profiles in the four combinations of height and orientation but differences in phenolic concentration and oxidative stability that increase with row spacing in NS hedgerows, consistent with those reported by Rodrigues et al. [24]. The wider $(2 \mathrm{~m})$ hedgerows which include additional canopy volume with low irradiance do not break the link between yield and quality that was evident in Figure 2. As seen in Figure 3, fruit are not found in heavily shaded parts

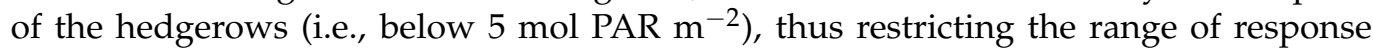
of oil quality parameters. In contrast, phenolic compounds do increase in response to improved irradiance in hedgerow orchards of wider compared to narrower spacings (Figure 5). Oxidative stability shows similar pattern to phenolic compounds but with smaller differences among row spacings.

These results reveal a significant superiority of the present model [20] in explaining the observed profiles of oil quality in olive orchards than in a previous irradiance model only applied to NS hedgerows [36]. In that case, the analysis was based upon surface irradiance on hedgerow walls without consideration of hedgerow porosity and subsequent irradiance within hedgerow canopies that differ greatly between orientations. In addition, light quality, e.g., far-red (FR)/ red ratio, which could potentially impact on oil quality is not included in the model. Little information is available. A recent manipulative study revealing the responsiveness of some vegetative traits in Arbequina plants to FR enrichments did not extend to reproduction and oil quality [37].

\section{Conclusions}

Hedgerow design (row orientation, height, width, spacing and porosity) determines canopy illumination and productivity but with less evident influence on fruit temperature in cv. Arbequina SHD orchards. Despite the existence of clear vertical profiles of oil quality parameters that can be explained in terms of irradiance, harvests of entire hedgerows produce oil of relatively constant fatty acid content across a range of row spacing and orientation. In contrast, phenolic compounds that contribute to oil oxidative stability, organoleptic and sensory characteristics do respond to orchard structure and increase with row spacing in NS-oriented hedgerows, apparently in response to greater irradiance on exposed fruit. That advantage is achieved, however, at yield considerably less than is possible in narrow-spaced hedgerows.

Simulations propose similar responses of overall orchard oil quality in taller and wider SHD orchards while identifying the need for more detailed information on the distribution of fruit within hedgerow canopies and associated irradiance. The lack of response of oil quality to orchard design seems to be related to the large sensitivity of fruit development to irradiance. Most fruit in hedgerows grow under high radiation conditions with consequent relatively homogeneous oil quality. The search for management options would benefit from improved modelling capacity over the coarse relationships currently available. Consideration of canopies in smaller volumes would increase precision, especially for short $(2 \mathrm{~m})$, narrow $(0.8-1.0 \mathrm{~m})$ hedgerows that are emerging as commercially favoured designs. The automated measurement of orchard structure and fruit distribution in these hedgerows in response to pruning may offer advantage to oil quality as well as to yield. 
Opportunities to manage oil quality exist elsewhere in choice of cultivar, for which few are currently available, time of harvest according to fruit maturity and location. Overrow harvesters can remove fruits independently of fruit retention force, allowing early harvest for high phenolic and oleic acid concentrations. In addition, olive-growing area can markedly influence oil quality, so further studies on the productivity of olive hedgerow systems would usefully include the consideration of oil quality.

Author Contributions: Conceptualization and methodology, M.G.-d.-C. and D.J.C.; data curation, M.G.-d.-C. and E.R.T.; irradiance modelling, D.J.C.; analysis of the data, D.J.C. and E.R.T.; writingoriginal draft, D.J.C., M.G.-d.-C. and E.R.T. All authors have read and agreed to the published version of the manuscript.

Funding: This research received no external funding.

Institutional Review Board Statement: Not applicable.

Informed Consent Statement: Not applicable.

Acknowledgments: We gratefully acknowledge "Casa de Hualdo" for access to olive orchards where this research was conducted. The companies Casas de Hualdo, Todolivo, Regaber and Agromillora financed the installation of the experiments. E.R.T. held a pre-doctoral fellowship from ERASMUSMundus.

Conflicts of Interest: The authors declare no conflict of interest.

\section{References}

1. Rallo, L.; Barranco, D.; Castro-García, S.; Connor, D.J.; Gómez-del-Campo, M.; Rallo, P. High-density olive plantations. Hortic. Rev. 2013, 41, 303-384.

2. Connor, D.J.; Gómez-del-Campo, M.; Rousseaux, M.C.; Searles, P.S. Structure, management and productivity of hedgerow olive orchards: A review. Sci. Hortic. 2014, 169, 71-93. [CrossRef]

3. Pastor, M.; Garcia-Vila, M.; Soriano, M.A.; Vega, V.; Fereres, E. Productivity ofolive orchards in response to tree density. J. Hortic. Sci. Biotechnol. 2007, 82, 555-562. [CrossRef]

4. Servili, M.; Selvaggini, R.; Esposto, S.; Taticchi, A.; Montedoro, G.; Morozzi, G. Health and sensory properties of virgin olive oil hydrophilic phenols: Agronomic and technological aspects of production that affect their occurrence in the oil. J. Chromatogr. A 2004, 1054, 113-127. [CrossRef]

5. Yaqoob, P. Monounsaturated fatty acids and immune function. Eur. J. Clin. Nutr. 2002, 56, S9-S13. [CrossRef] [PubMed]

6. Gómez-del-Campo, M.; García, J.M. Canopy fruit location can affect olive oil quality in "Arbequina" hedgerow orchards. J. Am. Oil Chem. Soc. 2012, 89, 123-133. [CrossRef]

7. Castillo-Ruiz, F.J.; Jiménez-Jiménez, F.; Blanco-Roldán, G.L.; Sola-Guirado, R.R.; Agüera-Vega, J.; Castro-Gacia, S. Analysis of fruit and oil quantity and quality distribution in high-density olive trees in order to improve the mechanical harvesting process. Span. J. Agric. Res. 2015, 13, 1-8. [CrossRef]

8. Grilo, F.; Caruso, T.; Wang, S.C. Influence of fruit canopy position and maturity on yield determinants and chemical composition of virgin olive oil. J. Sci. Food Agric. 2019, 99, 4319-4330. [CrossRef]

9. Llorente-Cortés, V.; Estruch, R.; Mena, M.P.; Ros, E.; González, M.A.M.; Fitó, M.; Badimon, L. Effect of Mediterranean diet on the expression of pro-atherogenic genes in a population at high cardiovascular risk. Atherosclerosis 2010, 208, 442-450. [CrossRef]

10. Rousseaux, M.C.; Cherbiy-Hoffmann, S.U.; Hall, A.J.; Searles, P.S. Fatty acid composition of olive oil in response to fruit canopy position and artificial shading. Sci. Hortic. 2020, 271, 109477. [CrossRef]

11. Gómez-del-Campo, M.; Connor, D.J.; Trentacoste, E.R. Long-term effect of intra-row spacing on growth and productivity of super-high density hedgerow olive orchards (cv. Arbequina). Front. Plant Sci. 2017, 8, 1790. [CrossRef]

12. Diez, C.M.; Moral, J.; Cabello, D.; Morelló, P.; Rallo, L.; Barranco, D. Cultivar and tree density as key factors in the long-term performance of super high-density olive orchards. Front. Plant Sci. 2016, 7, 1226. [CrossRef] [PubMed]

13. Vidal, A.M.; Alcalá, S.; de Torres, A.; Moya, M.; Espínola, F. Characterization of olive oils from superintensive crops with different ripening degree, irrigation management, and cultivar: (Arbequina, Koroneiki, and Arbosana). Eur. J. Lipid Sci. Technol. 2019, 121, 1800360. [CrossRef]

14. Marino, G.; Macaluso, L.; Marra, F.P.; Ferguson 1 Marchese, A.; Campisi, G.; Volo, P.; Laudicina, V.A.; Caruso, T. Horticultural performance of 23 Sicilian olive genotypes in hedgerow systems: Vegetative growth, productive potential and oil quality. Sci. Hortic. 2017, 217, 217-225. [CrossRef]

15. Marino, G.; Macaluso, L.; Grilo, F.; Marra, F.P.; Caruso, T. Toward the valorization of olive (Olea europaea var. europaea L.) biodiversity: Horticultural performance of seven Sicilian cultivars in a hedgerow planting system. Sci. Hortic. 2019, $256,108583$. [CrossRef] 
16. Larbi, A.; Ayadi, M.; Dhiab, A.B.; Msallem, M.; Caballero, J.M. Olive cultivars suitability for high-density orchards. Span. J. Agric. Res. 2011, 9, 1279-1286. [CrossRef]

17. Trentacoste, E.R.; Connor, D.J.; Hueso, A.; Gómez-del-Campo, M. Effect of row spacing on olive 'Arbequina' oil quality within north-south-oriented hedgerows. Acta Hortic. 2018, 1199, 459-464. [CrossRef]

18. Trentacoste, E.R.; Connor, D.J.; Gómez-del-Campo, M. Effect of row spacing on vegetative structure, fruit characteristics and oil productivity of N-S and E-W oriented olive hedgerows. Sci. Hortic. 2015, 193, 240-248. [CrossRef]

19. Uceda, M.; Frías, L. Harvest dates. Evolution of the fruit oil content, oil composition and oil quality. In Segundo Seminario Oleicola Internacional; COI: Córdoba, Spain, 1975; pp. 125-128.

20. del Río, C.; Romero, A. Whole, unmilled olives can be used to determine their oil content by nuclear magnetic resonance. HortTechnology 1999, 9, 675-680. [CrossRef]

21. Connor, D.J.; Gómez-del-Campo, M.; Trentacoste, E.R. Relationships between olive yield components and simulated irradiance within hedgerows of various row orientations and spacings. Sci. Hortic. 2016, 198, 12-20. [CrossRef]

22. Salas, J.J.; Sánchez, J.; Ramli, U.S.; Manaf, A.M.; Williams, M.; Harwood, J.L. Biochemistry of lipid metabolism in olive and other oil fruits. Progress Lipid Res. 2000, 39, 151-180. [CrossRef]

23. Criado, M.N.; Morelló, J.R.; Motilva, M.J.; Romero, M.P. Effect of growing area on pigment and phenolic fractions of virgin olive oils of the Arbequina variety in Spain. J. Am. Oil Chem. Soc. 2004, 81, 633. [CrossRef]

24. Rodrigues, N.; Casal, S.; Peres, A.M.; Baptista, P.; Bento, A.; Martín, H.; Pereira, J.A. Effect of olive trees density on the quality and composition of olive oil from cv. Arbequina. Sci. Hortic. 2018, 238, 222-233. [CrossRef]

25. Matsuki, M. Regulation of plant phenolic synthesis: From biochemistry to ecology and evolution. Aust. J. Bot. 1996, 44, 613-634 [CrossRef]

26. Cronin, G.; Lodge, D.M. Effects of light and nutrient availability on the growth, allocation, carbon/nitrogen balance, phenolic chemistry, and resistance to herbivory of two fresh water macrophytes. Oecologia 2003, 137, 32-41. [CrossRef] [PubMed]

27. Caruso, G.; Gucci, R.; Sifola, M.I.; Selvaggini, R.; Urbani, S.; Esposto, S.; Taticchi, A.; Servili, M. Irrigation and fruit canopy position modify oil quality of olive trees (cv. Frantoio). J. Sci. Food Agric. 2017, 97, 3530-3539. [CrossRef] [PubMed]

28. Lémole, G.; Weibel, A.M.; Trentacoste, E.R. Effect of shading in different periods from flowering to maturity on the fatty acid and phenolic composition of olive oil (cv. Arbequina). Sci. Hortic. 2018, 240, 162-169. [CrossRef]

29. Del Carlo, M.; Sacchetti, G.; Di Mattia, C.; Compagnone, D.; Mastrocola, D.; Liberatore, L.; Cichelli, A. Contribution of the phenolic fraction to the antioxidant activity and oxidative stability of olive oil. J. Agric. Food Chem. 2004, 52, 4072-4079. [CrossRef]

30. Dumas, Y.; Dadomo, M.; Di Lucca, G.; Grolier, P. Effects of environmental factors and agricultural techniques on antioxidant content of tomatoes. J. Sci. Food Agric. 2003, 83, 369-382. [CrossRef]

31. El Riachy, M.; Priego-Capote, F.; Rallo, L.; Luque-de Castro, M.D.; León, L. Phenolic composition of virgin olive oils in cultivars for narrow hedgerow olive orchards. Eur. J. Lipid Sci. Technol. 2013, 115, 800-810. [CrossRef]

32. Saudreau, M.; Marquier, A.; Sinoquet, H. Modelling fruit-temperature dynamics within apple tree crowns using virtual plants. Ann. Bot. 2011, 108, 1111-1120. [CrossRef] [PubMed]

33. Villalobos, F.J.; Testi, L.; Orgaz, F.; García-Tejera, O.; Lopez-Bernal, A.; González-Dugo, M.V.; Ballester-Lurbe, C.; Castel, J.R.; Alarcón-Cabañero, J.J.; Nicolás-Nicolás, E.; et al. Modelling canopy conductance and transpiration of fruit trees in Mediterranean areas: A simplified approach. Agric. For. Meteorol. 2013, 171, 93-103. [CrossRef]

34. García-Inza, G.P.; Castro, D.N.; Hall, A.J.; Rousseaux, C.M. Responses to temperature of fruit dry weight, oil concentration, and oil fatty acid composition in olive (Olea europaea L. var. Arauco). Eur. J. Agron. 2014, 54, 107-115. [CrossRef]

35. Sánchez Lucas, R. The Effect of Increasing Temperature on Olive Trees (Olea Europaea L. subsp. Europaea) Biology: An Integrated Morphological, Phenological and Biomolecular Study. Ph.D. Thesis, Universidad Córdoba, Córdoba, Spain, 2019.

36. Connor, D.J.; Gómez-del-Campo, M. Simulation of oil productivity and quality of N-S oriented olive hedgerow orchards in response to structure and interception of radiation. Sci. Hortic. 2013, 150, 92-99. [CrossRef]

37. Ladux, F.J.; Trentacoste, E.R.; Searles, P.S.; Rousseaux, M.C. Light quality environment and photomorphological responses of young olive trees. Horticulturae 2021, in press. 